\title{
ITINERARIO Y CRONOLOGÍA EN LA SEGUNDA PARTE DEL QUIJOTE
}

Uno de los temas que más han atraído la atención de los cervantistas ha sido el de la posible realidad histórica del relato contenido en el Quijote. Se reparten en dos grupos: el de los que buscan los antecedentes históricos de los personajes de la novela (en especial don Quijote y Sancho Panza, pero sin olvidar los secundarios: los duques, Carrasco, el del Verde Gabán) y el de los que intentan situar los pasos de don Quijote dentro de los espacios físico (geográfico), por un lado, y temporal (cronólogico), por el otro.

Dejaré de lado el primero de estos problemas (¿Existió de veras don Quijote?) y con respecto al segundo (sus caminos y sus días) sólo expondré algunas de las posibles soluciones que a mí me parecen, si no seguras, sí por lo menos dignas de ser tenidas en cuenta en otras pesquisas más detenidas ${ }^{1}$.

1 Ocuparía mucho espacio la relación y el examen de los trabajos que tratan de los itinerarios quijotescos y, además, no nos conduciría más que a unos mismos resultados, a saber: que, así como en la ruta de las dos primeras salidas hay más o menos uniformidad de criterios, con ligeras variantes en torno a la patria de don Quijote (más de una docena de villas han salido a escena) y la situación de tal o cual pasaje en particular (cada manchego tiene sus particulares opiniones sobre tal o cual venta) y uno o dos días de diferencia entre éste o aquel autor, en cambio la explicación del tiempo para la segunda parte o tercera salida la mayor parte de las veces es o bien pasada por alto por los comentaristas (a veces con silencio absoluto, que es una postura muy cómoda pero poco elegante) o bien despachada atribuyendo la imposibilidad de su fijación a los descuidos cervantinos. Quiero, por consiguiente, liberar al lector del tormento que supone tanto esfuerzo con resultado inútil. Por lo demás, las remisiones a la obra de los pasajes citados las hago mediante la aglutinación de una $Q$ de Quijote seguida de un 1 o un 2 de la primera o segunda partes y finalmente de dos dígitos indicativos del capítulo. 
Don Quijote se mueve en un espacio natural y conocido cual es el de las tierras manchegas (y en parte aragonesas y catalanas y hasta puede que andaluzas del norte) y sus tres salidas transcurren en una estación del año determinada, en verano. Esto está claro y se desprende de las mismas indicaciones que se hacen en la novela, y en manera alguna sorprende al lector medianamente atento. Lo más digno de notar es que, por más que en toda la obra no se mencionen, por lo que se refiere a los lugares, más que cuatro fijos y conocidos, y por más que los días que van pasando se indiquen sólo con escasísimas fechas concretas y claras referidas al calendario, sin embargo, en una lectura normal apenas se nota la carencia de más datos. El espacio físico y el tiempo están tan magistralmente supeditados a la acción y al personaje, y a la vez tan íntimamente ligados a él, que, como formando parte de su propia naturaleza, no son necesarias más explicaciones para saber todo cuanto debemos saber sobre la patria y el escenario y la época de las correrías de dQ.

Si bien se mira, todos los episodios del Quijote pueden ser inespaciales e intemporales. La importancia del mensaje cervantino no radica en que los molinos sean molinos manchegos ni en que tarde seis días en sanar de los arañazos gatunos. Lo que importa es el desacuerdo de la realidad con su fantasía y la crueldad de un castigo inmerecido, así provengan, estos contratiempos, de molinos o de arañazos. Pero también hay que convenir que, así como la diversidad existente entre los diversos episodios considerados aisladamente (molinos, rebaños, aguas del río, pastores, canónigos, comerciantes, duques) se tolera y hasta se agradece gracias al fondo que anima toda la obra, también se agradece, por necesaria, la ubicación de estos inverosímiles, casi materialmente imposibles, episodios en un espacio geográfico concreto, familiar si se quiere, y en un espacio temporal determinado, sabido, casi de antemano, por el lector. En una palabra: para que podamos creer en don Quijote, don Quijote tiene que ser un personaje posible. Y un personaje posible requiere lugar y tiempo.

Cervantes, naturalmente, comprendió esta necesidad de situar las aventuras quijotescas entre estas coordenadas de lugar y tiempo; pero, si bien habría podido, con su maestría, hacer que nuestro personaje fuera gallego o aragonés, por ejemplo, y situar sus hazañas en pleno invierno, creo que estaremos de acuerdo en agradecerle que lo situara en la Mancha y en que su locura se manifestara en pleno verano. "En tiempo de la siega», que dirá Sancho. Pero, a la vez, fiel a su sistema de dejar que nosotros mismos saquemos las conclusiones, una vez situado don Quijote en el corazón de la Mancha y sus andanzas en pleno verano, sólo de vez en vez, y como 
por casualidad, deja caer alguna noticia acerca de los lugares y de las calendas concretas en que le ocurren a don Quijote tantas cosas como las que le ocurren.

Y esta parquedad en noticias y la natural curiosidad que nos atormenta a los cervantistas, sobre todo a los meros aficionados como yo, es lo que ha dado pie a tantas preguntas y tantas posibles soluciones.

Las cuestiones del espacio y el tiempo en la primera parte del Quijote apenas crean ya problemas. Don Quijote emplea, en sus dos primeras salidas, exactamente 38 días, repartidos en 2 días para la primera, 18 días de descanso en casa y otros 18 para la segunda. El recuento se da minuciosamente en el relato. Tan minuciosamente como que los detalles que nos dice Cervantes, de ser el primer día viernes (recuérdese que "Acierta a ser viernes aquel día» y por esto en la venta le sirven bacalao, Q103) y caer el último en domingo (recuérdese la llegada a la aldea de don Quijote enjaulado a la mitad del día en que por ser domingo todo el vecindario se hallaba en la calle, Q152), marcan un espacio de tiempo de exactamente 38 días que van de un viernes al sexto domingo siguiente. Si a esto añadimos que la carta de don Quijote a Dulcinea, escrita el $26^{\circ}$ día de estos 38, está fechada en Sierra Morena el 22 de agosto, según la edición príncipe, o el 27 del mismo mes, según la rectificación de la edición de Bruselas de 1608, nos vemos obligados a situar la acción de la novela, puestos ya a atribuir (sólo a base de suposiciones) la máxima verosimilitud al relato cervantino, o bien en el año 1600 (caso de la carta fechada el 22), con los 38 días entre el 28 de julio (primer día) y el 3 de septiembre (último día), o bien en el año 1602 (caso de la carta fechada el 27), con los 38 días entre el 2 de agosto (primer día) y el 8 de septiembre (último día).

Son irrelevantes y no influyen para nada en el recuento exacto de estos días algunos desequilibrios momentáneamente temporales, involuntarios para unos, intencionados para otros, como, por ejemplo, que en un mismo día los huéspedes de la venta cenan dos veces, y hasta podríamos decir que tres. Está comprobado que hasta el último instante del trabajo de los cajistas en la imprenta pudo haber reescrituras de pasajes enteros o cambios en el orden de los episodios, y esto podría haber provocado esta anómala doble o triple cena, siempre, desde luego, que tales incorrecciones no fueran debidas, como opinan algunos críticos, a la propia intención de Cervantes de no entorpecer con insignificancias de tiempo real lo que para la narración requería una cierta intemporalidad o, más bien, una sola unidad de tiempo.

Aciertan los que proclaman que para Cervantes una cosa es el tiempo real y otra el narracional; pero desatinan cuando dedican 
una obra entera, o capítulos de otra, o trabajos sueltos, para demostrarlo, porque tamaña conclusión es válida para todos los literatos y autores de fantasías, creadores de mitologías y religiones.

Por lo que se refiere al espacio geográfico, las dudas son mayores, pues surgen ya por la ocultación voluntaria por parte de Cervantes de la patria de don Quijote, que ha dado origen a tantas suposiciones como han sido las cabezas pensantes, y acaban por el empecinamiento de los investigadores locales que, llenos de celo patriótico, han querido reconocer e identificar todas las ventas por donde pasó don Quijote y todos los bosques cuyos aromas confundió con sus suspiros amorosos.

Creo que estos problemas menores deben tenernos sin cuidado, como probablemente al mismo Cervantes le tenían sin cuidado. Si de mí dependiera, daría carta blanca a todas las ventas manchegas para que pudieran anunciar con orgullo que en ellas se alojaron don Quijote y Sancho. Es muy posible que al escribir cualquier escena ocurrida en una venta, al situar a su personaje pasando la noche en un bosque, o atacando unos molinos o siendo apaleado en un camino, Cervantes recordara alguna venta en particular, algún bosque donde acaso se refugiara alguna vez, algún molino de los que tenía que inspeccionar o algún recodo de algún camino donde su mula tropezara. Todo es posible. Pero opino que lo más sensato es pensar y creer que una venta es todas las ventas, un molino todos los molinos, un bosque todos los bosques y un camino todos los caminos. Como cualquier lugar de la Mancha puede ser y representar todos los lugares de la Mancha.

Y esto es válido para las dos partes. Sólo así tiene explicación por qué en toda la obra (ambas partes) sólo aparecen cuatro topónimos de lugares concretos por donde pasa don Quijote, y los cuatro cada vez con una significación bien notoria, a saber:

Dos accidentes naturales, Puerto Lápice y la Cueva de Montesinos, que contemplan, respectivamente, la primera confirmación de don Quijote como caballero andante (por su victoria sobre el vizcaíno) y la primera confirmación de su gloria caballeresca (por el reconocimiento por parte de Montesinos). Y dos agrupaciones humanas, el Toboso y Barcelona, que albergan, respectivamente, los dos grandes fracasos de don Quijote: como enamorado (imposibilidad de encontrar a Dulcinea) y como hombre de armas (derrota final). Y realmente no se necesitan más nombres para que el lector consiga establecer la plena composición de lugar necesaria para completar la verosimilitud del relato.

Ciertamente (hay que decirlo) aparecen en la obra, además de la Mancha, otros topónimos, pero todos son espacios abiertos, puestos como fondo por donde transcurre el relato: la Sierra Morena, 
«esta» Andalucía, Aragón, Cataluña; o bien sólo sirven como meros referentes para recordarnos que seguimos en los mismos escenarios, como Quintanar, el Viso, Almodóvar, o el mismo río Ebro, que don Quijote podría haber atravesado por tantos lugares diferentes.

Yo admito, no tanto por seguir con la tradición más extendida como porque bien puede adaptarse a la realidad que quiso imaginar Cervantes, yo acepto, digo, que don Quijote, fuera o no de allí, hiciera su primera salida de Argamasilla de Alba o de algún lugar próximo. Pero, cuidado: en toda la obra no se dice de manera expresa que Argamasilla de Alba fuera la patria de nuestro hidalgo y recordemos que los versos del final de la primera parte no autorizan en modo alguno a defender esta paternidad. Hay otras aldeas que pueden defender con más probabilidades de éxito su candidatura a ser la patria de don Quijote. Pero son tantas y hay, junto a indicios favorables, tantos inconvenientes para cada uno de estos lugares, que por ahora, mientras no se desempolven viejos y carcomidos archivos que nos den más luz, hemos de seguir la única pista que nos dio Cervantes: que el lugar era de la Mancha y que su autor arábigo ocultó intencionadamente su nombre para que don Quijote no fuera menos que Homero.

Sea lo que sea, aceptemos en principio que la aldea de don Quijote fuera Argamasilla de Alba como una de las más próximas a la de Dulcinea, el Toboso, por aquello que se dice que ella era «de un lugar cerca del suyo»(Q101). Con más o menos variaciones sobre la situación de tal o cual venta, tal o cual paraje de Sierra Morena y tal o cual instalación de batanes, y si creemos de veras lo que he dicho antes, que lo que interesa es "una» venta, «un bosque», «un camino», y no «esta» venta, «este» bosque, «este» camino, no resulta dificultoso trazar los itinerarios de don Quijote en sus dos primeras salidas. Y de hecho la mayoría de los que han dedicado sus esfuerzos en tal sentido más o menos coinciden.

No es mi propósito detenerme en enumerar los diferentes resultados que se han obtenido, ni siquiera discutirlos, porque, repito, en términos generales todos podrían ser aceptados. Pero sí voy a centrar la cuestión del espacio físico en una circunstancia que apenas ha sido vislumbrada por los críticos ${ }^{2}$. Y entro ya de lleno en los dos únicos puntos que me interesa aquí examinar.

2 No me atrevo a decir que nunca ha sido vislumbrada porque sé que en el campo de la investigación cervantina pocas veces puede uno presumir de haber descubierto algo nuevo. Se ha escrito, y se escribe, tanto que es materialmente imposible que una persona sola haya podido consultar toda la bibliografía cervantina. Yo aseguro que lo que voy a exponer no lo he visto en otros trabajos, pero no puedo asegurar que no haya otros que lo hayan expuesto antes. 
La segunda parte no presenta tantos problemas de posibles descuidos por acumulación de escenas en un mismo día. Apenas notamos el hecho, ya observado por los editores, de que don Quijote y Sancho llegan al castillo de los duques al atardecer y, eso no obstante, inmediatamente y sin interrupción, cenan y después Sancho departe con la duquesa, para lo cual ha tenido que saltarse la siesta de aquel día. No le demos importancia a este descuido porque puede ser debido a una refundición del pasaje.

De momento, vengo a decir que en la segunda parte de la obra ni en la sucesión de días (que se siguen de una manera rigurosamente exacta, sin saltarse ninguno solo, como veremos) ni en el itinerario o ruta geográfica, no se presentan más problemas que estos dos, en principio graves, a saber: la aparente dificultad de trazar el itinerario de los primeros días de esta tercera salida y la aparente imposibilidad del espacio temporal en su desarrollo total.

Comencemos por el trazado de la ruta de los primeros días de la tercera salida.

Dice el texto cervantino que nos ha llegado (pues no sabemos si hubo otro diferente) que don Quijote y Sancho al anochecer se ponen camino del Toboso, acompañados durante media legua por Sansón Carrasco, y luego, ya solos, toman la ruta de la gran ciudad del Toboso; pero temen que, a pesar de andar toda la noche, no alcanzarán ni siquiera a verla, y siguen hablando (y es de suponer que andando) y así se les pasa aquella noche. Y también pasan todo el día siguiente sin que les ocurra nada de particular, ni siquiera vislumbrar el Toboso. Solamente «al otro día al anochecer», es decir, al siguiente, cuando ya han transcurrido el anochecer del día de la salida, una noche, el segundo día entero, otra noche y todo el tercer día, descubren el Toboso y entran en el pueblo cuando ya ha oscurecido.

La tercera noche ocurre lo que sabemos en el Toboso, y, como se viene a más andar el día sin haber encontrado el palacio de Dulcinea, al amanecer del cuarto día abandonan el Toboso, y don Quijote se embosca en una floresta a dos millas de la gran ciudad, y Sancho regresa a ella con la intención de seguir buscando la casa de Dulcinea. Pero se queda meditando al pie de un árbol hasta que, siendo ya la tarde, descubre a las tres aldeanas y monta el más sutil engaño que jamás se haya visto. Desengañado don Quijote, aquella misma tarde prosigue su camino hacia Zaragoza; y se encuentra con la carreta de la Muerte, que aquella misma «mañana, que es la octava del Corpus», ha representado el auto en un pueblo y tiene prisa para representarlo en otro hacia donde se dirige.

El alcance de este encuentro con la Muerte lo veremos luego, porque lo que interesa ahora es seguir por los mismos pasos de 
noches y días de don Quijote y Sancho. Y, así (ya resumiendo), vemos que en los dos días siguientes les ocurre el encuentro con el Caballero de los Espejos, luego con el del Verde Gabán y los leones, y las bodas de Camacho y finalmente la bajada a la sima de Montesinos, el día $14^{\circ}$ de su salida. Y cuando aparece Maese Pedro ya están en la Mancha de Aragón.

Hasta aquí el relato según el texto de la obra.

Pues bien: los comentaristas han hecho de tripas corazón para intentar trazar un itinerario en que fueran de la mano la lógica, el tiempo y el espacio, pero no lo han conseguido porque se han empecinado en que la tercera salida don Quijote la hace desde Argamasilla de Alba (o en todo caso de otro pueblo de la zona). Y esto es un disparate, porque:

a) Resulta que de Argamasilla de Alba al Toboso hay una distancia de unos $40 \mathrm{~km}$., recorribles, a paso de mula de alquiler (o de Rocinante poco trotón), en un día, y sin embargo don Quijote y Sancho pierden en hacer el recorrido un atardecer, dos noches y dos días, sin paradas ni fondas.

b) Resulta también un contrasentido que, teniendo don Quijote intenciones de visitar la cueva de Montesinos, que está, como quien dice, pegada a Argamasilla de Alba, se aparte de ella siguiendo la ruta del Toboso hacia el norte para luego deshacer lo andado yendo hacia el sur.

c) Y resulta, finalmente (pero aún hallaríamos otras pequeñeces), que el mismo Cervantes insiste en manifestarnos que las aventuras de don Quijote en esta tercera salida comienzan «en el camino del Toboso", "como las otras comenzaron en los campos de Montiel». Camino del Toboso que no necesariamente tiene que partir de Argamasilla de Alba y menos si, como resulta con claridad de la lectura del texto, se halla fuera del campo de Montiel.

Si al tropezar con estas contradicciones o dificultades nos paramos a considerar otras singularidades de la obra y la más singular manera de proceder de Cervantes, tan proclive a despistar al lector y sobre todo a proponerle soluciones ambiguas a cada paso, podemos hallar, creo, otra explicación mucho más satisfactoria.

Nada más comenzar la primera parte Cervantes manifiesta no querer recordar el nombre de la aldea del hidalgo, y a punto de acabar la segunda manifestará que Cide Hamete ha ocultado expresamente la patria de don Quijote. Esto no obstante, los versos argamasillescos del final de la primera han inducido a los lectores a considerar a don Quijote como natural de Argamasilla de Alba, acaso con evidente error según el pensamiento, que desconocemos, 
de Cervantes. Siendo así la cosa, ¿no podemos pensar que quizás el burlón Cervantes podría haberse aprovechado de esta falsa interpretación nuestra, como lectores suyos, para proporcionarnos otra pista, precisamente para seguir despistándonos, y trazar, ya en la segunda parte, el itinerario de la tercera salida como si don Quijote saliera, sí, de Argamasilla, pero no de la de Alba, sino de la de Calatrava?

Argamasilla de Calatrava está a unos 130/140 km. del Toboso, distancia que para ser recorrida se necesitaba realmente los dos días con sus noches (de corto descanso) que se dicen en el texto de la novela, a paso de bestias. La cueva de Montesinos no cae en el mismo meridiano de Argamasilla de Calatrava y el Toboso (como cae en la del Toboso y Argamasilla de Alba) y una vez recorrido el trayecto no hay que desviarse con media vuelta completa para ir a la cueva. Y, finalmente, el camino que lleva de Argamasilla de Calatrava hasta el Toboso empieza muy lejos del Campo de Montiel, e incluso es muy factible hacer todo el trayecto sin pisar un solo palmo del Campo de Montiel (y me guío por el mapa de don Justiniano Rodríguez Castillo, que conoce la zona mejor que nadie) ${ }^{3}$.

¡Qué solución más cervantina! Don Quijote, manchego ciertamente. De un lugar que el autor no quiere recordar. Pero que el lector puede suponer que es de Argamasilla de Alba, de donde sale hacia el Campo de Montiel para sus primeras aventuras. Pero que luego resulta que no hay explicación posible de su tercera salida si la hace desde Argamasilla de Alba, y hay que pensar en otra Argamasilla, la de Calatrava. Tras lo cual nada queda definitivo pero todo resuelto: la patria de don Quijote en cualquier Argamasilla, la existencia de la academia argamasillesca a salvo, todas las salidas diferentes ajustadas a la realidad geográfica. Y los lectores que habíamos adelantado soluciones que el Cide Hamete quería ocultarnos, finalmente burlados. Cervantes puro en su propia pura salsa.

Alguien (no recuerdo quién) ha defendido que el lector en cierta manera viene a ser coautor de la obra. Creo que aquí podemos ir más lejos: que Cervantes se subleva, se rebela, contra esa posible coautoría de sus lectores, y les rectifica sus errores.

Quede claro que opino sinceramente que esta solución de la doble patria de don Quijote, Alba primero y Calatrava después, puede ser la única plausible. Por lo menos la única que puede sa-

\footnotetext{
3 Véanse, por ejemplo "El Campo de Montiel y don Quijote», en Actas del Tercer Congreso Internacional de la Asociación de Cervantistas (III-CINDAC), Menorca, 1997. Palma, 1998, pp. 235-251, y «Los caminos del Campo de Montiel en la época cervantina", trabajo presentado en el mismo IX Coloquio Internacional de la Asociación de Cervantistas (Villanueva de los Infantes, 1999).
} 
tisfacer los problemas del comienzo del itinerario de la segunda parte de la obra.

Pero más singular (y también más problemático) es lo que ocurre con el espacio temporal en esta segunda parte de la novela.

Para los que no tengan los datos frescos en la memoria se los recordaré por el mismo orden en que aparecen:

1. Don Quijote anuncia su intención de tomar parte en unas justas en Zaragoza en honor de San Jorge. [Recordemos que San Jorge es el 23 de abril.]

2. El cuarto día de la tercera salida don Quijote se encuentra con la carreta de la Muerte, que aquella mañana, que es la octava del Corpus, ha representado el auto en un pueblo y va con prisas porque aquella misma tarde tiene que representarlo en otro. [Recordemos que el Corpus cae en el jueves décimo día después del domingo de Pentecostés.]

3. La cacería en tierras ducales ocurre en la mitad del verano.

4. El octavo día que don Quijote y Sancho están en casa de los duques Sancho entrega a la duquesa una carta que lleva la fecha de 20 de julio de 1614 .

5. Cuatro días después, Sancho, ya gobernador de la ínsula, recibe una carta del duque fechada a las cuatro de la madrugada del día 16 de agosto (pero sin año).

6. También es verano cuando Sancho al salir del gobierno de la ínsula cae en una sima.

7. Don Quijote llega a Barcelona la víspera de San Juan. [Recordemos que San Juan se celebra el 24 de junio.] ${ }^{4}$.

8. El día siguiente (por tanto, el mismo día de San Juan) la cabeza encantada no puede hablar porque es viernes.

9. Desde que don Quijote y Sancho traman la tercera salida, en esta segunda parte, hasta que el primero fallece, transcurren 89 días, ni uno más ni uno menos, descompuestos así: 3 de preparativos, 83 desde que salen hasta que don Quijote, ya en casa, recobra el juicio, y 3 con don Quijote con el juicio sano hasta que muere.

\footnotetext{
4 Carece de todo fundamento la tesis de que la fiesta de San Juan mencionada cuando don Quijote llega a Barcelona $(Q 260)$ y ss.) se refiera a la conmemoración de su degollación, que la Iglesia recuerda el 29 de agosto, a pesar de haber sido defendida por algunos autores. Aparte de que entre la fecha de la carta del duque de 16 de agosto y el 29 de agosto median sólo 13 días y entre el $31^{\circ}$ día de la tercera salida (en que se menciona la carta ducal) y el $53^{\circ}$ (en que don Quijote llega a Barcelona) median 23 días, la dificultad mayor en admitir el 29 de agosto como día de la llegada de don Quijote a Barcelona estriba en que la degollación de San Juan jamás ha sido "festivo día" en Barcelona, como lo era el día que don Quijote llegó a la ciudad (Q262) y sigue siendo todavía la conmemoración del nacimiento de San Juan (24 de junio).
} 
Otros tres detalles que nos ayudarán, pero que contienen indicios sólo indirectos para situar el relato en el tiempo, son que:

10. Cuando nuestra pareja caminante se encuentra con los duques, éstos se hallaban ocupados en la caza de altanería y en el palacio hay un clérigo que les acompaña a la hora de la cena. [Veremos luego el alcance de esta coincidencia.]

11. Roque Guinard aparece «de hasta edad de treinta y cuatro años». [Notemos que había nacido el 1582.] Y

12. Se habla de los recientes decretos de la expulsión de los moriscos. [El último de los cuales se había dictado en 1614.]

Hay que considerar que el período de casi un mes que, según el relato, estuvo don Quijote convaleciente tras la vuelta de su segunda salida (final de la primera parte) hasta que emprendió la tercera (comienzo de la segunda parte), es mero recurso del autor para enlazar sin solución grave de continuidad el hilo de la novela, puesto que en manera alguna podemos suponer que un mes después de un verano vuelva a ser verano. Esto es forzoso y su explicación fácil. Y además hay un detalle que demuestra que Cervantes tenía bien presente que entre las acciones de la primera parte y de la segunda hay por lo menos unos diez años de diferencia: en la primera parte se dice que el ama "pasaba de los cuarenta» años, frase que puede significar unos 41 años (Q101), y en la segunda es la propia ama la que confiesa "sobre los cincuenta años que tengo de edad» (Q273), que nos hace suponer que ya los había pasado.

Lo que no resulta tan fácil es ajustar las referencias a momentos de tiempo concreto dadas en esta segunda parte a una cronología más o menos posible que contemple la salida alrededor de la octava del Corpus, que suele caer entre fines de mayo y primeros de junio, para estar el 23 de abril en las fiestas de San Jorge de Zaragoza; ni una carta fechada el 20 de julio y la siguiente a los cuatro días el 16 de agosto; ni las fechas de estas cartas con la llegada de don Quijote a Barcelona más de un mes antes, el 23 de junio; etc.

Todo esto ha creado tal cúmulo de preguntas al parecer imposibles de contestar que los comentaristas todos han optado por salirse por el camino más cómodo atribuyendo estas aparentes contrariedades a que a Cervantes le tenía sin cuidado el tiempo real con tal de preservar el tiempo narrativo para cada escena.

Esto es una perogrullada, pues, como ya he insinuado, en toda la narrativa de ficción desde que el hombre es hombre el tiempo vivido corre por un lado y el tiempo imaginado por otro. $\mathrm{Y}$ hay tiempos míticos, y tiempos religiosos, y tiempos caballerescos. $\mathrm{Y}$ 
tiempo relativo. $\mathrm{Y}$ tiempos al uso de cualquier particular, podemos añadir.

Pero es que, si bien podemos considerar que Cervantes no es ninguna excepción a este principio, también resulta chocante la meticulosidad con que cuenta los períodos y los días en todos los momentos de su personaje. No hay (o por lo menos yo no conozco) ninguna novela del siglo de oro donde con tanta exactitud se cuenten los días y se mesuren los tiempos. No se salta ni un solo episodio sin asignarle su tiempo. A cada momento se cuida muy bien el autor de indicarnos, siempre por días, su duración y de cada una de sus incidencias. Comenta Gaos, y con razón, que Cervantes se salta los primeros cincuenta años de don Quijote, pero a partir de que lo saca a escena ya «sabremos lo que don Quijote y Sancho hacen hora a hora y día a día» ${ }^{5}$. Podemos decir con seguridad de no equivocarnos que la tercera salida de don Quijote consta de 3+83+3 días, en total 89. Sólo en esta segunda parte, donde estamos, hay nada menos que unas 110 menciones de plazos referidos a días (otro día, que significa «el día siguiente»; tantos días; al enésimo día, etc.), y unas ochenta menciones referidas a momentos del día o de la noche (al amanecer, a la tarde, etc.). No hay episodio, no hay situación, que no se hallen medidos por días.

Siendo así, ¿cómo es posible pensar que al lado de tanta meticulosidad se incurra luego en tantos manifiestos errores de fechas, que hacen suponer que don Quijote sale por los días del Corpus, mayo/junio, y a los pocos el duque escribe una carta fechada el 16 de agosto y luego don Quijote llega a Barcelona el 23 de junio, víspera de San Juan?

Si no abundase el recuento de los días en cada episodio con tanta insistencia (y hasta repetición), uno podía pensar que realmente a Cervantes no le importaba orden o ambiente temporal de la novela.

Pero ¿tan poco en cuenta le tenía este orden temporal y tan descuidadamente iba componiendo la obra que, habiendo situado a sus personajes entre el 20 de julio y el 16 de agosto (fechas de las dos cartas) en casa de los duques, treinta días después los sitúa en Barcelona uno o dos meses antes, el 23 de junio?

No es posible imaginar tanto desequilibrio en una obra que se caracteriza por su insistencia en dejar bien claramente situados en el espacio temporal cada uno de los pasos de don Quijote. Y esto nos incita a intentar buscar una solución a esta aparente contradicción.

5 Véase su edición del Quijote. Madrid, 1987, tomo III (de Apéndices), p. 100. 
Sin querer sentarla como definitiva, voy a proponer una solución que califiqué yo mismo de posible tras la lectura de un artículo de la profesora Aurora Egido y que, a mi juicio, cuadra muy bien con todo lo que hasta ahora sabemos de la novela y de las circunstancias en que fue escrita ${ }^{6}$.

De los doce puntos referenciales que he mencionado antes, pronto podemos eliminar el primero, el que hace mención de las justas por San Jorge en Zaragoza, por varios motivos:

1. Porque, como luego don Quijote decide no ir a Zaragoza, no forma parte del relato.

2. Porque no necesariamente tenían que ser, estas justas, las de 23 de abril, ya que la cofradía de San Jorge celebraba a menudo hasta tres competiciones en un mismo año y en diferentes fechas. Y

3. Porque, aunque quisiéramos investigar las fechas históricas por los años probables de la tercera salida de don Quijote (sólo para disponer de un dato más aunque irrelevante), la investigación podría resultar inútil porque Cervantes, cuando había acudido a ellas como marco para la aventura final de don Quijote, lo había hecho diez años antes, al terminar la primera parte, y no podemos saber si podía haberse referido a algunas justas de las que tendría noticias por aquellas fechas o al hecho de las justas en general.

No crean ningún problema otros dos puntos, el 3 y el 6 , que nos recuerdan que la acción pasa en verano. Esto es evidente. Además, con ello Cervantes se adapta al tiempo caballeresco, de larga tradición heredada seguramente de los romanos, que sólo combatían en verano y se recluían, para repostar, en invierno. Es también indiferente la verdadera acepción de la palabra "verano" en tiempo de Cervantes. Mientras para muchos comentaristas el año podía estar dividido en cinco estaciones de las que la llamada «verano» correspondería a una intermedia entre la primavera y el estío actuales, lo cierto es que las dos veces que aparece la mención del verano es para acentuar que se trata de época de calor: en el episodio de la cacería se lamenta de no ser la noche «tan clara ni tan sesga como el tiempo pedía»(Q234), y cuando Sancho cae en la sima no le da pesadumbre pasar la noche al descubierto porque era en verano (Q255).

6 EgIDo, AURoRA, "Zaragoza y don Quijote o el espacio contra el tiempo», incluido en Cervantes y las puertas del sueño. Barcelona, 1994, pp. 223-229, y aparecido antes (al parecer con el título de «Don Quijote en Zaragoza o el espacio contra el tiempo») en Caracola, Revista ultramarina, 3/4, 1989, pp. 26-31. 
Dejo aparte, para el final, las desconcertantes fechas de las dos cartas, puntos 4 (20 de julio de 1614) y 5 (16 de agosto, sin año), no sin tomar en consideración, empero, el dato muy significativo del año de 1614 dado a la primera de las cartas, la de Sancho a Teresa.

Quedan, pues, los restantes puntos, y, como con ellos es imposible trazar un itinerario temporal que se avenga, siguiendo los principios normales de todos los itinerarios, con la salida cerca de la festividad del Corpus y la llegada a Barcelona la víspera de San Juan, no queda más remedio, si suponemos que Cervantes siguió otra conducta fija determinada, que explorar en el terreno de la anormalidad. Anormalidad que, empero, pueda ser siempre justificada con las circunstancias en que se encontró Cervantes al momento de componer la segunda mitad de la segunda parte.

Adelanto ahora la posible solución que propongo para este problema y luego la justificaré con unas asombrosas coincidencias que la avalan.

Primero.-En primer lugar contemplamos:

A) Que Cervantes continuó, en la segunda parte de la obra, con la idea anunciada al final de la primera parte, de llevar a don Quijote hasta Zaragoza, según se repite unas nueve veces durante los primeros 48 capítulos. Pero,

B) Que, una vez enterado del plagio de Avellaneda, que se le había adelantado llevando al falso don Quijote a Zaragoza, decidió cambiar todos los rumbos del verdadero, el suyo, a saber: no sólo cambiar el rumbo en el espacio físico, geográfico, llevando, como anuncia en el capítulo 49 y cumple en los siguientes, a don Quijote hasta Barcelona, sino también, y esto es lo que me parece a mí una novedad, cambiar el rumbo en el espacio temporal, haciendo que a partir de aquel mismo momento el tiempo le corra a don Quijote marcha atrás. Con ello se crea un evidente paralelismo entre espacio físico y espacio temporal, pues de la misma manera que a partir de la noticia del falso Quijote el auténtico se aleja geográficamente de Zaragoza, también a partir del mismo momento se aleja cronológicamente del posible día de las justas zaragozanas. Así, pues, marcha atrás en el espacio al que le corresponde una marcha atrás en la cronología. El juego resulta perfecto y en él encajan, como veremos, todos los demás datos que avaramente nos proporciona Cervantes en su relato.

Segundo.-En segundo término, también podemos contemplar:

C) Que, si aplicamos las andanzas al año de la fecha que lleva la carta de Sancho a Teresa, o sea 1614, todo, absolutamente todo, 
ensambla a la perfección como una delicada obra de ebanistería, sin que quede un resquicio. Y también

D) Que la edad de Roque Guinard y la mención de los recientes decretos de la expulsión de los moriscos, nos ayudan a confirmar el año de 1614 como el de la tercera salida de don Quijote. De Roque Guinard se dice que aparentaba 34 años. Había nacido en 1582 y tenía, pues, sólo 32, y, si bien había sido indultado en 1611, es muy probable que la noticia no hubiera llegado aún a Castilla, donde vivía Cervantes. En cambio sí debía conocer bien Cervantes los últimos decretos de expulsión de los moriscos, el último de los cuales era de 1614 .

Veamos las coincidencias que con mi teoría se producen y que son las que han hecho romper una lanza en su favor.

Hay que empezar por determinar la primera de las fechas que nos da Cervantes en esta segunda parte. Se trata de la octava del Corpus, cuando tiene lugar el encuentro con la carreta de la Muerte. Casi todos los comentaristas pasan en silencio esta mención o bien, acaso, se limitan a comentar que la festividad del Corpus caía en el jueves de la octava siguiente a la de Pentecostés y casi siempre a fines de mayo o principios de junio. Pero una de las ediciones más modernas, la del Instituto Cervantes ${ }^{7}$, comete el error de situar la octava del Corpus en el octavo día siguiente al mismo día del Corpus, y añade que era costumbre representar los autos sacramentales el día del Corpus en las grandes ciudades y los días siguientes, binando inclusive, en las aldeas. Pero no es así. No es así y el comentarista de este capítulo se equivoca porque no ha tomado en consideración dos cosas: La primera que la «octava» era, en tiempos de Cervantes, no el octavo día siguiente a una festividad, como se entiende ahora, sino, como definía aún el Diccionario de Autoridades en 1739, el «Espacio de ocho días, durante los cuales celebra la Iglesia la festividad de algún santo", etc. O sea, prácticamente la semana dentro de la cual caía esta festividad. La acepción de "octava» como el día octavo de la festividad es relativamente moderna, de fines del siglo pasado. En catalán conservamos todavía solamente la primera de estas acepciones: el espacio de ocho días de una fiesta, el primero de los cuales es el de la propia fiesta. No podía, por consiguiente, el cómico Angulo referirse solamente al octavo día siguiente al del Corpus. Y la segunda cosa en que yerra el tal comentarista está en que sitúa el hecho de binar los cómicos por los pueblos en los días posteriores al Corpus, cuando no hay prueba alguna de que así sea, sino todo al contra-

7 Dirigida por Francisco Rico. Barcelona, 1998. 
rio: que cuando más menudeaban las representaciones era precisamente el sábado del Corpus, el mismo día del Corpus y acaso el día siguiente. Por consiguiente, cuando Angulo dice que aquel día es la octava, quiere decir que está dentro de la octava del Corpus, es decir, dentro de sus ocho días; y cuando especifica que ha representado por la mañana en un pueblo y tiene prisa por representar por la tarde en otro, nos proporciona una probabilidad más en favor de que aquel mismo día es el día del Corpus, y no otro.

Y el Corpus, en 1614, cayó exactamente el 29 de mayo.

Si aplicamos esta fecha, 29 de mayo de 1614 , al $4^{\circ}$ día de la tercera salida, que es cuando se encontraron don Quijote y la Muerte, tendremos que esta tercera salida se inició el lunes 26 de mayo de 1614, después de haberla preparado don Quijote durante los tres días anteriores (23, 24 y 25 de mayo). Y, siguiendo por sus mismos días y pasos, se produce otra curiosa coincidencia: que don Quijote y Sancho llegan a casa de los duques el $21^{\circ}$ día de su salida, que justamente es domingo, y encuentran a los duques ocupados en la caza de altanería; y se halla en el castillo un clérigo (que luego discutirá con don Quijote). Pues bien: ya no puede ser más curioso que en este hecho se produzcan tantas coincidencias, como las que vamos a ver.

Sabido es que la caza de altanería, o de cetrería, estaba reservada a personajes reales, príncipes y nobles de elevado rango, y he leído en alguna parte (pero no he podido recordar la cita) que era costumbre practicarla en domingos y días festivos. Y resulta que este $21^{\circ}$ día, el de la llegada de don Quijote en tierras de los duques, era, ya lo he dicho, domingo. Pero lo que sí está comprobado es que la caza en domingo sólo estaba tolerada por la Iglesia, según opinión bastante extendida, si por la mañana se había cumplido con el precepto dominical ${ }^{8}$. Y esto justificaría la presencia del clérigo en casa de los duques, aquel domingo, $21^{\circ}$ día de la tercera salida de don Quijote. Por más que (y es otra coincidencia) jamás faltaba en los palacios y casas de gente principal de las afueras un clérigo que iba los domingos a oficiar y además a ayudar a echar las cuentas. Y más, todavía: que era corriente la bula pontificia a favor de los oratorios particulares de otorgar validez del precepto dominical a los oyentes con tal de que también comieran en la misma casa o castillo del oratorio ${ }^{9}$. Y esto podía haber dado origen a la comida/

8 Desconozco muchas de las costumbres de la caza, y más de los siglos pasados. Debo mucha información sobre algunos de sus usos al profesor Alberto del Río Noguera, quien ha tenido la cortesía de facilitarme algunas referencias muy útiles.

9 Esta especie de autorización sujeta a condición hace poco seguía vigente. Me consta de ciencia propia porque en mi casa - que es la vuestra-disponemos de una bula en parecidos términos otorgada por Pío XII. 
cena de aquel mismo día de los duques con don Quijote y el propio cura que habría celebrado la misa dominical.

Tal cúmulo de circunstancias no constituye, lo reconozco, ninguna prueba definitiva de que aquel día fuera un domingo, concretamente el domingo 15 de junio de 1614. Pero no podemos dejar de pensar en tantas coincidencias a la vez para sumarlas a las otras que también encontraremos.

Siguiendo el mismo hilo de la novela, vemos que el $28^{\circ}$ día de la salida, cuando ya han regresado de la cacería del jabalí que ha roto el vestido nuevo de Sancho, éste da a la duquesa una carta que dice haber escrito. La escena ocurre por la mañana de ese día $28^{\circ}$ de la tercera salida, que cae en domingo 22 de junio, y lleva fecha de 20 de julio de 1614 . Y esta fecha suscita dos dudas:

Primera duda, por el día. Día 20, dice; pero Sancho la entrega a la duquesa el día 22. Sin embargo la fecha del 20 es correcta, pues la carta tenía que haberse escrito con toda seguridad el día 20, como lo demuestra que en ella Sancho explica a su mujer que ha de darse los 3.300 azotes que la noche anterior, la de la cacería del jabalí, le había impuesto Merlín, «menos cinco, que me he de dar», o sea, que aún no se los ha dado, y estos cinco se los dará más tarde, el 21, según explicará a la duquesa cuando el 22 le entrega la carta y le dice que se los dio «anoche», o sea, el 21. Es, pues, correcta la fecha del 20.

Y segunda duda, por el mes. La carta dice «julio» y estamos en junio. Francamente no le encuentro más explicación razonable que una de estas dos: o error de una letra por parte del cajista o costumbre de Cervantes de insertar en sus escritos, a modo de morcillas, la fecha del día en que los escribía. Prefiero quedarme con la primera explicación, sin desechar del todo, empero, la segunda.

Sigamos adelante. El $31^{\circ}$ día de su salida, que resulta ser el miércoles 25 de junio, el duque escribe una carta a Sancho anunciándole espías en la ínsula y le da la fecha del 16 de agosto, sin año. Permítaseme que reserve esta otra extraña coincidencia de esta fecha para más adelante.

El $42^{\circ}$ día don Quijote y Sancho dejan el palacio ducal. Es exactamente el día central de los 83 de la tercera salida. Se ha llegado a la mitad del tiempo y es muy probable que en este momento Cervantes supiera ya con certeza la existencia de la continuación de Avellaneda. Porque el día siguiente don Quijote y Sancho llegan a la venta y don Quijote descubre que anda por ahí un falso don Quijote, al que hay que dar una lección. Y ya todos sabemos la decisión que toma.

Pues bien, si a partir de este $43^{\circ}$ día, seguimos la ruta geográfica que aleja a don Quijote de Zaragoza y le aplicamos la ruta 
cronológica que le aleja de la fecha fatal de su descubrimiento y de la posibilidad de las justas zaragozanas, es decir, si contamos a la inversa, nos encontramos con sorpresas no menos asombrosas que las anteriores:

Pues, mientras con una cronología normal, es decir, a derechas, don Quijote habría llegado, en su día $53^{\circ}$ de salida, a Barcelona una víspera de un San Juan que habría caído el 17 de julio, cosa materialmente imposible, en cambio con la cuenta hacia atrás a partir del día de su descubrimiento del falso don Quijote (el $43^{\circ}$ como queda dicho), resulta que llega a Barcelona en su mismo día $53^{\circ}$, claro está, pero que ahora cae exactamente la víspera de San Juan, que es el 24 de junio, y además en viernes, como se nos advierte en el episodio de la cabeza encantada.

Ítem más. Así como de haber seguido la cronología normal don Quijote después de haber llegado a su aldea y caído enfermo habría sanado de su locura el último día, el $83^{\circ}$, que habría sido el 16 de agosto (o sea, oh extraña coincidencia también, jel mismo día de la carta del duque a Sancho!), en cambio con la cronología inversa ese día coincide exactamente con el mismo día de su tercera salida, 26 de mayo.

Finalmente, notemos otra particularidad: que, así como antes de su tercera salida don Quijote ha perdido tres días en prepararla, ahora, una vez vuelto a ser Alonso Quijano, tarda otros tres días también en morirse. Es decir, en su tercera, definitiva y última salida, se cumple a la perfección, en todos los sentidos y en los más pequeños detalles, el supuesto de la novela circular propugnado por algunos estudiosos.

Y para concluir:

Sé que esta posición mía es muy atrevida y arriesgada y que será mirada con reservas por los cervantistas, hartos, como estamos, de simbolismos y, modernamente, de aplicaciones psicoanalíticas aplicadas al Quijote; y yo mismo, así como la solución de las dos Argamasillas me atrevo a defenderla como la única posible, en cambio esta del tiempo atrás en la segunda mitad de la segunda parte de la obra sólo me atrevo a proponerla como hipótesis de trabajo. La considero sólo "posible» gracias a tres factores: a) la necesidad de cohonestar la meticulosidad del tiempo contado y medido por Cervantes en cada uno de los episodios de su personaje con la aparente anarquía de algunas fechas de estos mismos episodios; $b$ ) la gran coincidencia de datos como los que he expuesto; y c) la genialidad cervantina, capaz de disfrazar la «normalidad» con apariencias "anormales», para tormento de sus lectores: nos obliga a forzar la imaginación para retorcer el tiempo. 
Si no es así, ¿a qué se debe el continuado esfuerzo, el insistente empeño de Cervantes en recordarnos en cada momento el paso de don Quijote a través de días y horas expresamente contados, todo ello en medio de una aparente profusión de anacronismos y "disparates» cronológicos? No se explica, si no es a cambio de obligar al lector, insisto en ello, a cometer otro aparente «disparate» más, pero que resulta que no es tal, sino un resultado estrictamente lógico y consecuente con la finalidad perseguida, a saber: que a partir del momento en que don Quijote verdadero se encuentra con el falso, para más contradecirlo no sólo se aleja de él en el espacio físico y deja Zaragoza para irse a Barcelona, sino también en el espacio temporal y se olvida del paso natural del tiempo para acabar contando marcha atrás los días del resto de su ruta.

Dejo la puerta abierta para los que, considerando posible esta solución, se atrevan a examinarla con más detenimiento.

José MaRÍa CASASAYAS

Asociación de Cervantistas 